\title{
Ellipsometry of nickel hydroxide electrodes formed by ex situ chemical precipitation. Potential routine and time effects *
}

\author{
J.O. Zerbino, C. De Pauli ${ }^{\star}$, D. Posadas and A.J. Arvia ${ }^{\dagger}$ \\ Instituto de Investigaciones Fisicoquímicas Teóricas y Aplicadas (INIFTA), Facultad de Ciencias Exactas, \\ Universidad Nacional de La Plata, Sucursal 4, Casilla de Correo 16, 1900 La Plata (Argentina)
}

(Received 30 August 1991; in revised form 3 December 1991)

\begin{abstract}
Ellipsometric and reflectivity data combined with voltammetric data have been obtained at $546.1 \mathrm{~nm}$ for different nickel hydroxide electrodes in $0.01 \mathrm{M} \mathrm{NaOH}$ at $25^{\circ} \mathrm{C}$. The electrodes were prepared by ex situ chemical precipitation on a polished platinum substrate. The influence of the potential routine applied to the nickel hydroxide electrode on the corresponding optical parameters and time effects for both the oxidized and reduced forms of the active material kept at constant potential have been investigated. The nickel hydroxide layer is described as a mixture of nickel(II) hydroxide, nickel(III) hydroxide and electrolyte-water domains. The kinetic effects are discussed through a complex reaction pathway involving different nickel(II) and nickel(III) hydroxide species, the processes starting preferentially at the borders of the different domains.
\end{abstract}

\section{INTRODUCTION}

One of the earliest applications of ellipsometry to electrochemical systems concerned the study of the nickel hydroxide electrode in $5 \mathrm{M} \mathrm{KOH} \mathrm{[1-3]} \mathrm{and} \mathrm{in} 0.1$ $\mathrm{M} \mathrm{KOH} \mathrm{[4]} \mathrm{and} \mathrm{NaOH}$ [5]. In recent ycars these studies werc extended by combining ellipsometry with other surface analysis $[6,7]$ and optical techniques [8-16] to achieve a more complete description of the reaction mechanisms and phase transformations associated with the nickel hydroxide electrode under a

\footnotetext{
* Dedicated to Professor Roger Parsons on the occasion of his retirement from the University of Southampton and in recognition of his contributions to electrochemistry.

** Facultad de Ciencias Químicas, Universidad Nacional de Córdoba, Córdoba, Argentina.

+ To whom correspondence should be addressed.
} 
number of different operating conditions. Thus more comprehensive ellipsometric data were obtained by using $\alpha-\mathrm{Ni}(\mathrm{OH})_{2}$ electrodes cathodically deposited on platinum, carbon and nickel [4,17-19]. Accordingly, new interpretations for the oxidized and reduced nickel hydroxide layer structures could be advanced. The dynamics of the optical properties of nickel in $5 \mathrm{M} \mathrm{KOH}$ was followed by ellipsometry and interpreted in this case through a two-layer model [20].

Despite the relatively large number of previous studies of the subject, it becomes rather difficult to compare the different results within a common single coherent physico-chemical framework. This is perhaps due to the fact that the system is by itself extremely complicated [18]. As a matter of fact it is likely that the proper characteristics of $\mathrm{Ni}(\mathrm{OH})_{2}$ layers used in different studies are not exactly the same, except perhaps in those cases in which the layer has been cathodically produced and its optical properties determined by in situ procedures. Frequently, nickel hydroxide layers have been described as crystalline materials [21] and occasionally as colloidal layers [22,23] containing either stoichiometric or non-stoichiometric compounds. From the optical and catalytic standpoints it appears reasonable to consider at least those layers formed through precipitation from solution as being constituted by a composed material, as seems to be the case for other hydrous metal oxide layers [24,25].

The present work presents ellipsometric and reflectivity data of different nickel hydroxide electrodes obtained by ex situ chemical precipitation on a polished platinum substrate, paying special attention to the influence of the potential routine applied to the nickel hydroxide electrode on the corresponding optical parameters and determining time effects for both the oxidized and reduced forms of the active material kept at constant potential. These results can contribute to a more critical assessment of the ellipsometric data available for the nickel hydroxide electrode.

\section{EXPERIMENTAL}

The working nickel hydroxide electrodes were prepared on a pretreated platinum substrate by repetitive precipitation from alternate immersions of $5 \mathrm{~s}$ each in $2 \times 10^{-3} \mathrm{M} \mathrm{NiSO}_{4}$ and $10^{-2} \mathrm{M} \mathrm{NaOH}$. To produce nickel hydroxide layers of different thicknesses, the number of immersions, $N$, in each solution was varied from 10 to 75 . The nickel hydroxide electrode obtained in this way exhibited good adherence to the substrate. The latter consisted of a flat platinum disc $\left(1.13 \mathrm{~cm}^{2}\right.$ geometric area) embedded in a polytetrafluoroethylene (PTFE) holder. The platinum disc was first cleaned in a $1: 1 \mathrm{H}_{2} \mathrm{SO}_{4}+\mathrm{HNO}_{3}$ mixture, then gradually polished to a mirror surface by using water suspensions of fine grain alumina powders (1.0, 0.3 and $0.05 \mu \mathrm{m})$, later subjected to ultrasonics and finally rinsed thoroughly with triply distilled water. Before running the electrochemical and optical measurements, the nickel hydroxide electrodes were immersed for a few seconds in $10^{-2} \mathrm{M} \mathrm{NaOH}$ under smooth stirring conditions. 
All solutions were prepared from p.a. (Merck) reagents and triply distilled water. Runs were made at $25^{\circ} \mathrm{C}$ in $10^{-2} \mathrm{M} \mathrm{NaOH}$ under purified $\mathrm{N}_{2}$ gas saturation.

Potentials were measured employing a hydrogen reference electrode in the same solution, but in the text they are referred to the standard hydrogen electrode (SHE) scale. The counterelectrode was a platinum wire spiral previously cleaned in hot concentrated $\mathrm{HCl}$ and heated in the reducing zone of the gas burner. The three-electrode electrochemical glass cell design was suitable for both optical and electrochemical experiments. In this case the Pt/precipitated $\mathrm{Ni}(\mathrm{OH})_{2}$ electrode was placed horizontally in the main cell compartment, the latter being provided with two plane glass windows, as described elsewhere [24].

The electrolysis cell was mounted in a Rudolph Research 437-02/200B manual ellipsometer (maximum resolution $0.01^{\circ}$ ) provided with a $150 \mathrm{~W}$ tungsten lamp with a filter $(546.1 \mathrm{~nm})$ and an RCA 1P-21 photomultiplier. The incidence light beam angle was fixed at $69^{\circ}$ and that of the compensator at $135^{\circ}$ with a $90^{\circ}$ retardation resulting from the use of a Babinet Soleil.

Voltammetric measurements were made at different scan rates $v$ in the range $0.001 \leq v \leq 0.1 \mathrm{~V} \mathrm{~s}^{-1}$ between fixed lower $\left(E_{\mathrm{s}, \mathrm{c}}\right)$ and upper $\left(E_{\mathrm{s}, \mathrm{a}}\right)$ switching potentials covering the $\mathrm{H}$ and $\mathrm{O}$ atom electrosorption-electrodesorption potential ranges on platinum and the $\mathrm{Ni}(\mathrm{OH})_{2} / \mathrm{NiOOH}$ redox couple potential range. The purpose of these experiments was to select the potential regions suitable for optical measurements during the charging-discharging cycles.

The ellipsometric readings at the polarizer $(P)$ and at the analyser $(A)$ under extinction conditions were converted to $\Delta$ and $\Psi$ by the usual procedure [26]. These values were derived from the following operation sequence.

(1) Ellipsometric measurements of a freshly prepared nickel hydroxide electrode at $E_{\mathrm{oc}}$, the open-circuit potential $\left(0.18<E_{\mathrm{oc}}<0.22 \mathrm{~V}\right)$, were made.

(2) The working electrode was held at $E_{1}=-0.70 \mathrm{~V}$ for a time $\tau=3 \mathrm{~min}$ to reach stable $\Delta$ and $\Psi$ values. The corresponding results were in agreement with those obtained at $E_{\text {oc }}$.

(3) A linear potential scan at $0.1 \mathrm{~V} \mathrm{~s}^{-1}$ was applied from $E_{\text {oc }}$ up to $0.83 \mathrm{~V}$ and held at this value for $\tau=5 \mathrm{~min}$ to electro-oxidize the nickel hydroxide layer completely so that its ellipsometric parameters could be determined. Longer times $\tau$ were avoided owing to the possible interference of oxygen evolution with the ellipsometric readings.

(4) Afterwards, the potential-current $(E-I)$ response was recorded from $0.83 \mathrm{~V}$ downwards to evaluate the nickel(III) electroreduction charge in the nickel hydroxide layer. In this case the potential was swept downwards to $-0.70 \mathrm{~V}$, then upwards to $0.18 \mathrm{~V}$ and held at this potential for several minutes. At $0.18 \mathrm{~V}$ no electroadsorption of $\mathrm{O}$ adatoms on platinum takes place. The $\Delta$ and $\Psi$ values at $0.18 \mathrm{~V}$ differed by less than $0.2^{\circ}$ from those of the initial nickel hydroxide electrode. This relatively small difference confirmed that the variations in $\Delta$ and $\Psi$ observed in the $0.18-0.83 \mathrm{~V}$ range are due mainly to changes in the nickel hydroxide layer. Accordingly, the influence of the platinum substrate on the 
ellipsometric data can be neglected even at the lowest nickel hydroxide layer thicknesses, as further described.

(5) To show the influence of the potential routine applied to the electrode on the values of $\Delta$ and $\Psi$, the working electrode potential was cycled at $0.1 \mathrm{~V} \mathrm{~s}^{-1}$ between -0.7 and $0.83 \mathrm{~V}$. After a certain number of oxidation-reduction cycles (ORCs), the values of both $\Delta$ and $\Psi$ were obtained at 0.18 and $0.83 \mathrm{~V}$. These potential values are related to the reduced and oxidized forms of the nickel hydroxide layer respectively. The influence of the holding time at $0.18 \mathrm{~V}$ on the ellipsometric data was also studied.

(6) Finally, the nickel hydroxide layer was dissolved by adding $\mathrm{H}_{2} \mathrm{SO}_{4}$ solution to obtain the $\Delta$ and $\Psi$ values of the platinum substrate. These readings were used as the reference for each series of experiments, so that in this way errors resulting from misalignment of the electrochemical cell could be minimized.

Reflectivity data complementing the voltammetric and ellipsometric data were also made by setting the analyser, the polarizer and the compensator aligned at $0^{\circ}$ (p-polarized light). The transient reflectivity was obtained within a fraction of a second.

The evaluation of $\Delta$ and $\Psi$ together with the relative reflectivity change $\Delta R / R$ allow one in principle to determine unequivocally $n$, the real part of the refractive index, $k$, the absorption coefficient, and $d$, the nickel hydroxide layer thickness.

It was assumed that either a homogeneous nickel hydroxide film is present or the number and size of the particles which constitute the layer remain nearly the same during the ORCs so that any change in the light scattering produced by these particles does not appear in the $\Delta R / R$ values. Furthermore, the $R$ values determined at $0.83 \mathrm{~V}$, particularly for thick nickel hydroxide layers, are so small that poor accuracy was obtained.

\section{RESULTS}

\section{Voltammetric data}

The voltammogram of the $\mathrm{Pt} / \mathrm{Ni}(\mathrm{OH})_{2}$ electrode in $10^{-2} \mathrm{M} \mathrm{NaOH}$ (Fig. 1) at 0 $\mathrm{V} \mathrm{s}^{-1}$ between $E_{\mathrm{s}, \mathrm{c}}=-0.70 \mathrm{~V}$ and $E_{\mathrm{s}, \mathrm{a}}=0.83 \mathrm{~V}$ shows in the -0.7 to $0.1 \mathrm{~V}$ range the contributions of the $\mathrm{H}$ and $\mathrm{O}$ adatom electrosorption processes on platinum and in the $0.3-0.8 \mathrm{~V}$ range the anodic (II) and cathodic (III) conjugated current peaks related to the $\mathrm{Ni}(\mathrm{II}) / \mathrm{Ni}(\mathrm{III})$ redox system. In the present case the voltammetric charge contribution of the $\mathrm{Ni}(\mathrm{II}) / \mathrm{Ni}$ (III) system is always larger than that of $\mathrm{H}$ and $\mathrm{O}$ atom electrosorption processes.

In gencral, the features of these voltammograms agree with those already described in previous publications [12,14], although in this case it was found that systematically the anodic $\left(Q_{\mathrm{a}}\right)$ to cathodic $\left(Q_{\mathrm{c}}\right)$ charge ratio related to peaks II and III was slightly greater than unity. This fact might be due in part to a poor baseline correction for peak II and in part to an initial excess of $\mathrm{OH}^{-}$ions in the nickel hydroxide layer resulting from the preparation procedure. 


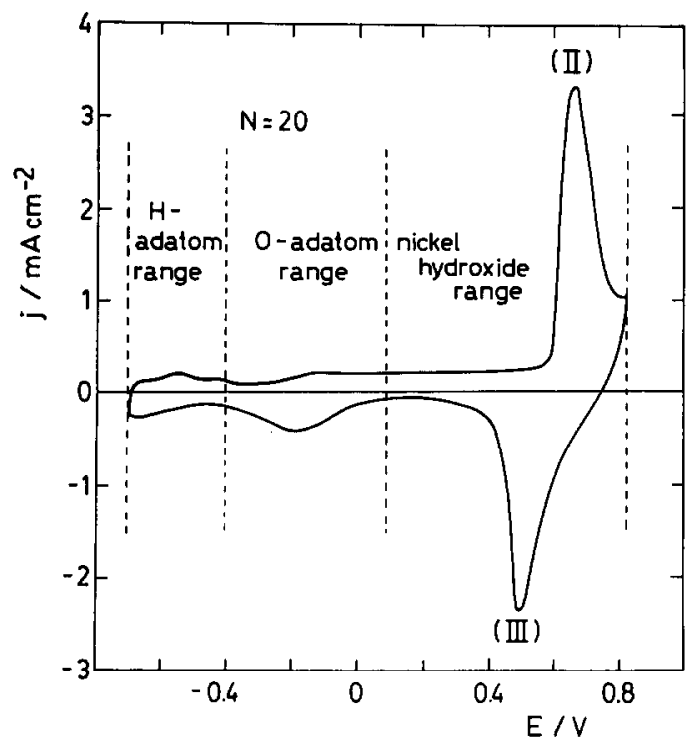

Fig. 1. Voltammetric response of the Pt/Ni(OH) 2 electrode; $v=0.1 \mathrm{~V} \mathrm{~s}^{-1}, 10^{-2} \mathrm{M} \mathrm{NaOH}, N=20$.

\section{Ellipsometric data}

Complementary ellipsometric data on platinum substrate

In order to ascertain the possible influence of the platinum substrate on the ellipsometric data, the values of $\Delta$ and $\Psi$ were determined at 0.18 and $-0.70 \mathrm{~V}$ for the bare platinum substrate, i.e. for the platinum electrode covered by $O$ adatoms and partially covered by $\mathrm{H}$ adatoms respectively [27].

The charge density involved in the anodization of platinum at $0.83 \mathrm{~V}$ was 1.77 $\mathrm{mC} \mathrm{cm}-2$. On the assumption that the oxide layer on platinum can be represented as either PtO $\left(\delta_{\mathrm{PtO}}=14.1 \mathrm{~g} \mathrm{~cm}^{-3}\right)$ or $\mathrm{PtO}_{2}\left(\delta_{\mathrm{PtO}_{2}}=10.2 \mathrm{~g} \mathrm{~cm}^{-3}\right)$, the resulting oxide layer thickness values $d$ are 1.30 and $1.02 \mathrm{~nm}$ respectively. Furthermore, the experimental changes in $\Delta$ and $\Psi$ in the absence of the $\mathrm{Ni}(\mathrm{OH})_{2}$ layer in going from the bare platinum to the platinum-oxide-covered surface are $\delta \Delta=2.8^{\circ}$ and $\delta \Psi=0.3^{\circ}$. With these values for the PtO layer one obtains a refractive index (real part) $n=2.5$ and an absorption coefficient $k=0.005$. The corrections which have to be made to the $\Delta$ and $\Psi$ values resulting for the $\mathrm{Pt} / \mathrm{PtO} / \mathrm{Ni}(\mathrm{OH})_{2}$ system are relatively small as compared to the values of $\Delta$ and $\Psi$ related to the $\mathrm{Ni}(\mathrm{OH})_{2}$ layer itself, which are between $17^{\circ}$ and $60^{\circ}$. Nevertheless, these corrections were taken into account in all the ellipsometric calculations shown here. It should be noted that the values of $n$ and $k$ referred to above for PtO are comparable with the values $n=2.1$ and $k=0.005$ already reported by Gottesfeld and Srinivasan [27] for PtO layers grown for $140 \mathrm{~min}$ at $2.2 \mathrm{~V}$ to $8.0 \mathrm{~nm}$ thickness. 


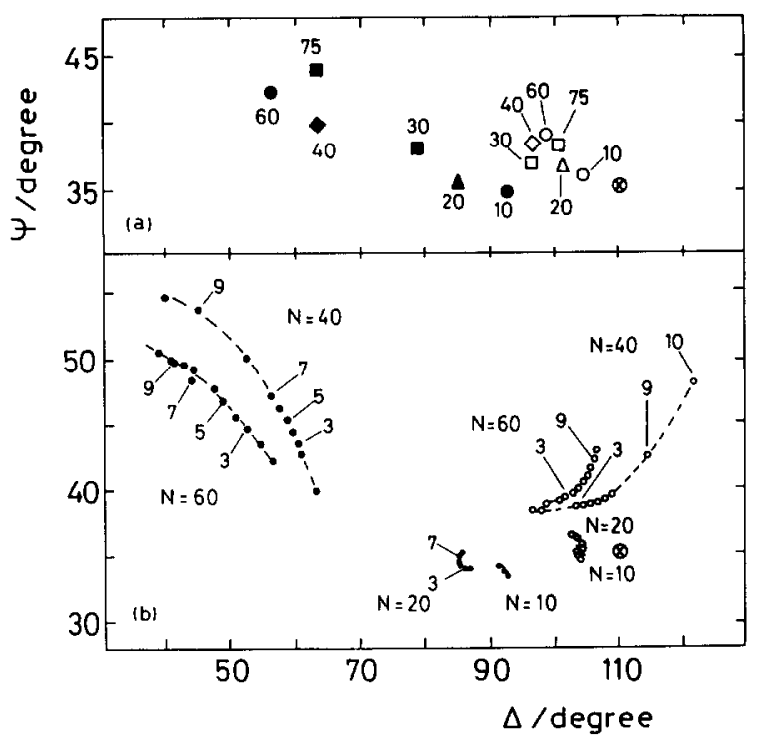

Fig. 2. $\Delta$ vs. $\Psi$ plots resulting for different numbers of immersions, $N=10-75$. $\otimes$ corresponds to the platinum substrate. (a) Open circles, $E_{1}=0.18 \mathrm{~V}$; full circles, $E_{\mathrm{u}}=0.83 \mathrm{~V}$. (b) Dependence of optical parameters on potential cycling for $N=10,20,40$ and 60 . The numbers indicate the time sequence of the readings.

\section{Nickel hydroxide layers}

The conventional $\Delta$ vs. $\Psi$ plots resulting for both the initial nickel hydroxide electrode at $E_{1}=0.18 \mathrm{~V}$ and after the first oxidation half-cycle up to $E_{\mathrm{u}}=0.83 \mathrm{~V}$ depend considerably on both the value of $N$ (Fig. 2(a)) and the number of ORCs (Fig. 2(b)). For $N>20$, as the number of ORCs increases, the ellipsometric data shift in the direction of increasing $\Psi$ and $\Delta$ for the electroreduced form but in the direction of decreasing $\Delta$ and increasing $\Psi$ for the electro-oxidized form. The greatest changes in $\Delta$ and $\Psi$ as compared to the substrate correspond to the oxidized form of the nickel hydroxide.

On the other hand, when the potential cycling is interrupted and the applied potential held at $0.18 \mathrm{~V}$, one can observe that the value of $\Delta$ remains practically constant while the value of $\Psi$ decreases with the potential holding time. This time effect of the ellipsometric parameters can be related to slow changes occurring in the nickel hydroxide layer in the electroreduced form after the ORCs, as described next.

ORC effect on the ellipsometric parameters

The preceding results (Fig. 2(b)) show that the ellipsometric parameters, particularly those read at $E=0.18 \mathrm{~V}$, depend on the characteristics of the ORCs. This fact indicates the necessity of studying further the influence of the ORCs on $\Delta$ and 


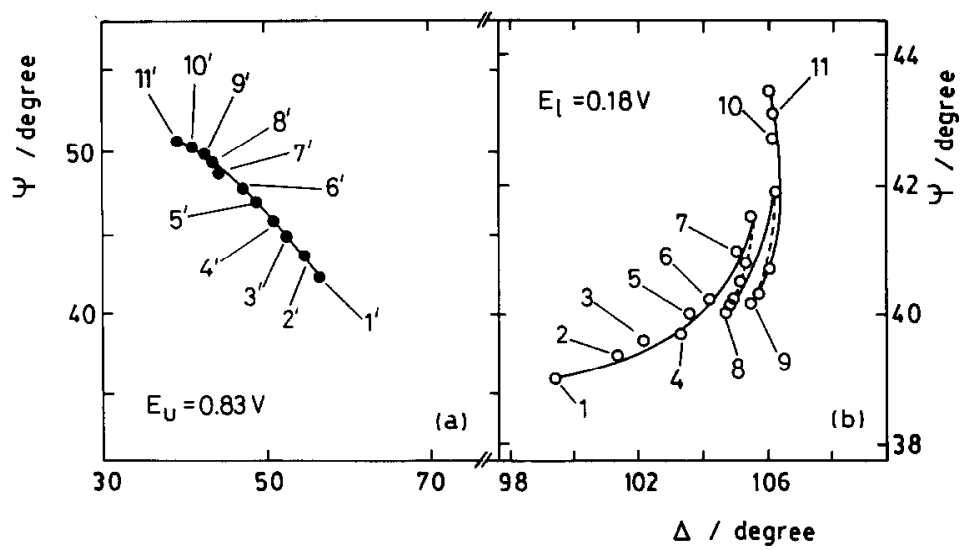

Fig. 3. Dependence of $\Delta$ vs. $\Psi$ at (a) $E_{\mathrm{u}}$ and (b) $E_{1}$ during potential cycling. The broken traces in (b) correspond to the time evolution of $\Delta$ and $\Psi$ during potential holding at $E_{1}$. The numbers indicate sequential readings.

$\Psi$. For this purpose the electrode was first subjected to several ORCs with intermediate potential holdings at either $E_{1}$ or $E_{\mathrm{u}}$ to determine $P$ and $A$. These results can be plotted for the reduced $\left(E_{1}\right)$ and oxidized $\left(E_{\mathrm{u}}\right)$ forms (Fig. 3). The numbers in Figs. 3(a) and 3(b) stand for sequential readings. The results obtained at $E_{\mathrm{u}}=0.83 \mathrm{~V}$ show an increase in $\Psi$ and a decrease in $\Delta$ along the potential cycling at $0.1 \mathrm{~V} \mathrm{~s}^{-1}$. In contrast, the results obtained at $E_{1}=0.18 \mathrm{~V}$ show an increase in both $\Delta$ and $\Psi$ along the potential cycling. Furthermore, when the cycling is interrupted at $E_{1}$, a considerable decrease in $\Psi$ is observed (broken traces in Fig. 3(b)). Even after 90 min (point 8, Fig. 3(b)) the values of $\Delta$ and $\Psi$ do not reach those of the fresh nickel hydroxide layer (hysteresis effect). Within the time scale of these experiments hysteresis can be seen in these $\Delta$ vs. $\Psi$ plots for the electro-oxidized 'form of the nickel hydroxide layer either starting from a non-relaxed or a relaxed electroreduced form.

These results show clearly that from the optical viewpoint, although the system has relaxed to some extent during the potential holding in the reduced state, after one ORC is applied it immediately regains its previous condition in the oxidized state. Thus the oxidation of the layer after the potential holding occurs as if the observed relaxation process in the reduced state had not happened.

\section{Reflectivity measurements}

The preceding results suggested the investigation of the influence of the applied potential over a much shorter time scale through reflectivity data, particularly at $E_{u}$. For this purpose the electrode was subjected to the potential shown in Fig. 4 (inset). The value of $\Delta R / R$ changes along the potential cycling and with the number of cycles (Fig. 4(a)). The greatest changes in $\Delta R / R$ appear in the 


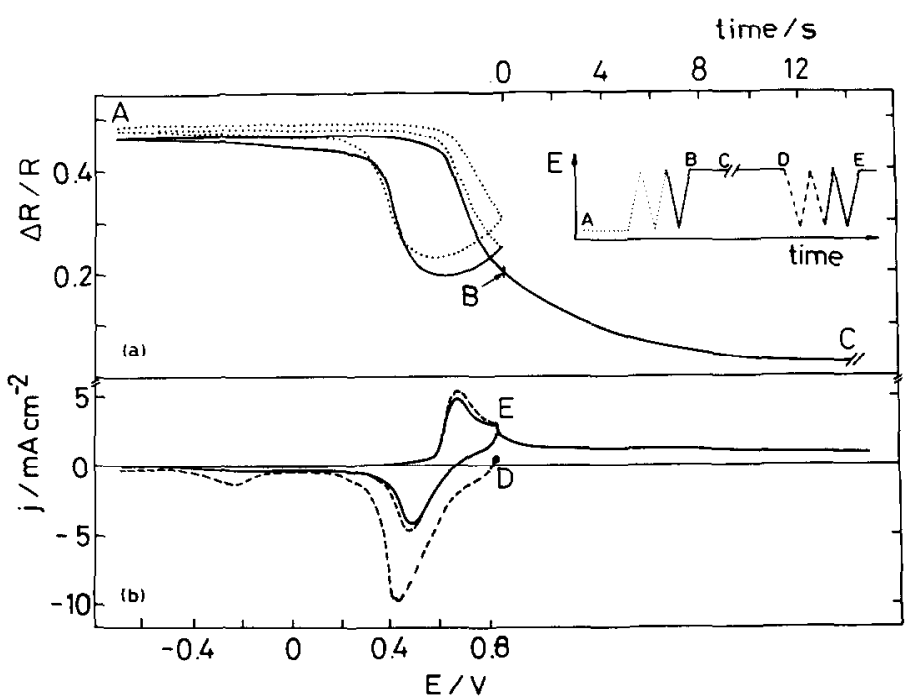

Fig. 4. (a) $\Delta R / R$ and (b) current changes during application of potential programme shown in inset; $v=0.1 \mathrm{~V} \mathrm{~s}^{-1}$.

potential range of the $\mathrm{Ni}(\mathrm{II}) / \mathrm{Ni}(\mathrm{III})$ redox couples (Fig. 4(b)). When the potential is held at $E_{\mathrm{u}}, \Delta R / R$ decays to attain a stationary value (Fig. 4(a)). After 5 min potential holding (point $\mathrm{D}$ ), the subsequent cycles show changes in the reflectivity with the number of potential cycles, though smaller than those seen initially. These changes are accompanied by an increase in the reduction charge of the oxide during the first potential cycle (broken line in Fig. 4(b)). The present experiment demonstrates that the changes in $R$ are produced mainly by the potential holding at $E_{\mathrm{u}}=0.83 \mathrm{~V}$. Voltammetric data indicate that most of the reflectivity changes caused by the potential holding should be related to a further increase in the amount of oxidized material in the layer. The potential holding at $E_{\mathrm{I}}$ leads to a slow increase in the reflectivity, as expected according to the results depicted in Fig. 3. This means that irreversible changes have occurred in the layer as a consequence of the positive potential holding.

\section{INTERPRETATION OF RESULTS}

Evaluation of the optical constants of the nickel hydroxide layer in the electroreduced and electro-oxidized forms

Results indicate that the changes in $\Delta$ and $\Psi$ in going from 0.83 to $-0.70 \mathrm{~V}$ or vice versa are due to the electro-oxidized and electroreduced forms of the nickel hydroxide layer. Accordingly, the corresponding ellipsometric behaviour can be simulated by considering as a first approach a homogeneous thickness-independent 


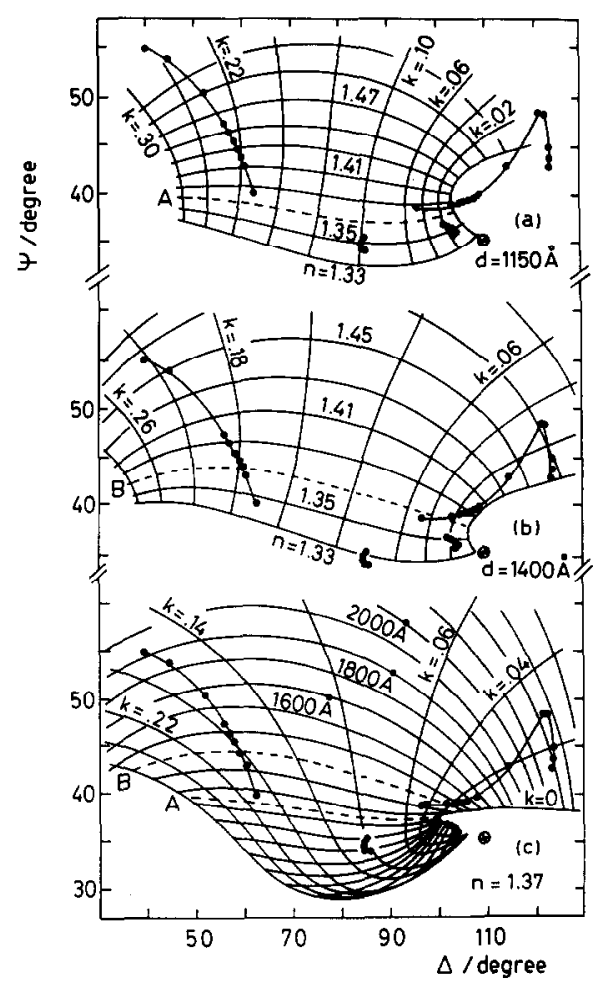

Fig. 5. Theoretical $\Delta$ vs. $\Psi$ plots obtained on the basis of a two-layer model; $\mathrm{Pt} / \mathrm{PtO} /$ nickel hydroxide. $\otimes$ corresponds to the platinum substrate. (a) $d=115 \mathrm{~nm}$, (b) $d=140 \mathrm{~nm}$ and (c) $n=1.37$.

nickel hydroxide single-layer structure. In this case $n$ and $k$, both at the wavelength $\lambda$, and $d$, the average thickness of the nickel hydroxide layer, are the only three parameters entering into the calculation. The subindices $O$ and $R$ identify the oxidized and reduced states respectively. The calculation of the $\Delta$ vs. $\Psi$ plots at constant $d$ for different values of $N$ was done by changing systematically the values of $k$ and $n$ (Figs. 5(a) and 5(b)). It can be observed that for a particular value of $d$ the initial values of $\Delta$ and $\Psi$ for different $N$ (Fig. 2(a)) for the oxidized and reduced forms lie on the lines of a common value of $n$, in agreement with previous work [12]. Moreover, as $N$ increases, the resulting values of $n$ and $k$ lie in the range $1.33<n_{\mathrm{O}, \mathrm{R}}<1.41,0.05<k_{\mathrm{O}}<0.22$ and $0.02<k_{\mathrm{R}}<0.05$. For $N>40$ these values of $n$ and $k$ are comparable with those reported earlier in the literature $[1,2,12]$.

As a second approach the $\Delta$ vs. $\Psi$ plots were calculated assuming $n$ was independent of $N$, with $k$ and $d$ taken as variables for the oxidized and reduced forms (Fig. 5(c)). The rest of the parameters were calculated for the oxidized and reduced forms for the different values of $N$ (Tables 1 and 2). 
TABLE 1

Data resulting for the reduced form of nickel hydroxide $(0.18 \mathrm{~V})$ at $\lambda=546.1 \mathrm{~nm}$ for $n=1.37$

\begin{tabular}{llc}
\hline$N$ & $k_{\mathrm{R}}$ & $d_{\mathrm{R}} / \mathrm{nm}$ \\
\hline 10 & 0.02 & $10-20$ \\
20 & 0.02 & $20-30$ \\
30 & 0.02 & 30 \\
40 & 0.02 & 130 \\
40 & 0.04 & 130 \\
50 & 0.02 & 160 \\
60 & 0.03 & 140 \\
75 & 0.03 & 135 \\
80 & 0.03 & 145 \\
\hline
\end{tabular}

There is no linear correlation between the values of $d_{\mathrm{O}, \mathrm{R}}$ and either $Q_{\mathrm{c}}$ or $N$. However, except for small values of $Q_{\mathrm{c}}$, the values of $d_{\mathrm{O}}$ and $d_{\mathrm{R}}$ are approximately the same and independent of both $Q_{\mathrm{c}}$ and $N$.

The values of $n_{\mathrm{R}}$ reported in the literature for $\alpha-\mathrm{Ni}(\mathrm{OH})_{2}$ are in the range $1.40 \leq n_{\mathrm{R}} \leq 1.50[8,9]$. The difference from the present results can be presumably assigned to the different preparation procedure of the nickel hydroxide layers. The value of $k_{\mathrm{O}}$ is in reasonable agreement with the values previously reported by Ord at $632.8 \mathrm{~nm}$ in $5 \mathrm{M} \mathrm{KOH}[10,12]$.

An alternative analysis of the data is also possible by introducing other simplifying assumptions and considering the whole set of data for different $N$. In view of the results obtained above, it can be assumed that for the nickel hydroxide layer in both the oxidized and reduced states the values of $n$ and $d$ are common to both states, i.e. $n_{\mathrm{O}}=n_{\mathrm{R}}=n$ and $d_{\mathrm{O}}=d_{\mathrm{R}}=d$. Then it is possible to calculate the remaining parameters $k_{\mathrm{O}}, k_{\mathrm{R}}, n$ and $d$ at each $N$.

These results are summarized in Fig. 6 by plotting $d, k_{\mathrm{O}}$ and $n$ as a function of $Q_{\mathrm{c}}$ for $k_{\mathrm{R}}<0.03$. It appears that both $n$ and $k_{\mathrm{o}}$ approach limiting values as $Q_{\mathrm{c}}$ is increased, whereas $d$ fluctuates around a $Q_{\mathrm{c}}$-independent constant value $(d=120$ $\mathrm{nm})$.

TABLE 2

Data resulting for the oxidized form of nickel hydroxide $(0.83 \mathrm{~V})$ at $\lambda=546.1 \mathrm{~nm}$ for $n=1.37$

\begin{tabular}{llll}
\hline$N$ & $k_{\mathrm{O}}$ & $d_{\mathrm{O}} / \mathrm{nm}$ & $Q_{\mathrm{c}} / \mathrm{mC} \mathrm{cm}^{-2}$ \\
\hline 10 & 0.075 & 70 & 2.10 \\
20 & 0.10 & $90-100$ & 4.00 \\
30 & 0.19 & 115 & 5.38 \\
40 & 0.19 & 120 & 14.7 \\
40 & 0.18 & 135 & 15.9 \\
50 & 0.16 & 135 & 16.7 \\
60 & 0.22 & 130 & 22.8 \\
75 & 0.17 & 135 & 24.8 \\
80 & 0.31 & 115 & - \\
\hline
\end{tabular}




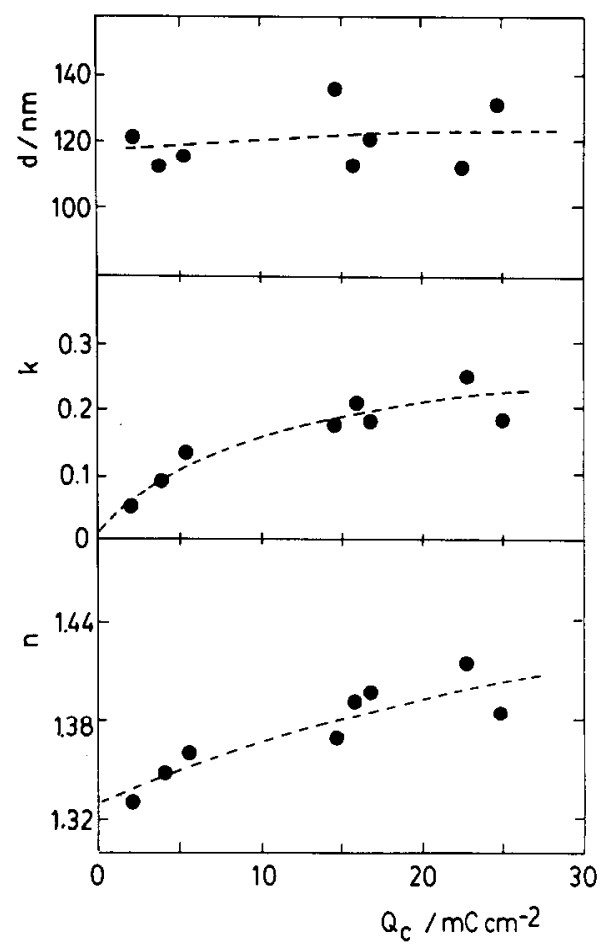

Fig. 6. Dependence of computed optical parameters $n, k$ and $d$ on cathodic charge $Q_{\mathrm{c}}$.

Effect of potential cycling on the ellipsometric parameters

The results displayed in Figs. 2(b) and 5 under potential cycling conditions cannot be interpreted straightforwardly because the three basic parameters required in the calculations could change simultaneously.

During cycling, the values of $\Delta$ and $\Psi$ at $E_{\mathrm{u}}$ move in the directions of increasing $d_{\mathrm{O}}$ or $n_{\mathrm{O}}$, and similarly for $d_{\mathrm{R}}$ and $n_{\mathrm{R}}$ at $E_{\mathrm{l}}$. The higher the shifts, the greater is the value of $N$. Most probably the observed changes in the ellipsometric parameters on potential cycling would be due to a progressive change in both $n$ and $d$. Small changes in $d$ are not uncommon when changing the oxidation state of active films on electrodes and are usually associated with changes in the chemical structure of the film $[28,29]$.

DISCUSSION

\section{Preliminary consideration}

A simple correlation of the ellipsometric and voltammetric parameters for the oxidized and reduced forms of $\mathrm{Ni}(\mathrm{OH})_{2}$ films obtained by chemical precipitation 
as well as a straightforward interpretation of the data are not possible. It is known that the amount of $\mathrm{Ni}(\mathrm{OH})_{2}$ film produced by chemical precipitation increases with $N$, but the ellipsometric data are apparently consistent with a constant $\mathrm{Ni}(\mathrm{OH})_{2}$ film thickness which becomes independent of $N$, whereas the values of $n$ and $k$ of the reduced form increase with $N$.

On the other hand, the effect of potential cycling on the ellipsometric parameters is more evident for high values of $N$ and, being an accumulative effect, for high numbers of ORCs. For $N>20$ (Fig. 5) the changes in $\Delta$ and $\Psi$ suggest changes in $n$ and $d$ for the oxidized form of the film, whereas for the reduced form there is, besides changes in $n$ and $d$, also a probable increase in $k$.

The experiments with negative potential holding show that the change in the ellipsometric parameters is due to a slow further electroreduction of a nickel(III) (either $\beta$ - or $\gamma-\mathrm{NiOOH}$ or both) species.

The experiments with positive potential holding show that a relatively fast further oxidation process occurs during the potential holding. The combination of this process with the slow reduction should be related to the accumulative effects observed during the potential cycling.

For a rational approach to the interpretation of the data, let us consider the following main aspects

(1) the probable composition and homogeneity of the initial $\mathrm{Ni}(\mathrm{OH})_{2}$ film and its changes during the ORCs;

(2) the possible reasons for the appearance of hysteresis effects by holding the potential at either $E_{\mathrm{u}}$ or $E_{1}$;

(3) the possible stationary situation which may be considered as appropriate for the estimation of optical parameters for both the oxidized and reduced forms of the $\mathrm{Ni}(\mathrm{OH})_{2}$ film;

(4) the relationship between ellipsometric and voltammetric results in terms of reaction mechanisms discussed earlier.

\section{Composition and homogeneity of $\mathrm{Ni}(\mathrm{OH})_{2}$ films}

A number of electrochemical and in situ optical investigations [22-25] support a composite gel-like structure for $\mathrm{Ni}(\mathrm{OH})_{2}$ layers produced by either chemical or electrochemical precipitation on conducting substrates.

The growth of nickel hydroxide through chemical precipitation should involve in the early stages a nucleation and growth process at the substrate surface and further thickening outwards (see e.g. ref. 30). Therefore, except for very thin nickel hydroxide layers, the active material can be considered as confined to a nearly constant volume defined by the area of the substrate and the layer thickness.

The fact that the ellipsometric data of the $\mathrm{Ni}(\mathrm{OH})_{2}$ layer under open circuit and without any precedent electrochemical perturbation are consistent with a nearly constant film thickness, particularly for relatively large amounts of $\mathrm{Ni}(\mathrm{OH})_{2}$, would suggest that as the number of immersions increases, the growing of other nuclei at the outer boundary becomes possible. The formation of these nuclei should 
contribute to make the nickel hydroxide layer thicker and more compact. For a range of high values of $Q_{\mathrm{c}}$ (or $N$ ) the value of $d$ derived from ellipsometry becomes independent of the amount of active material participating in the ORCs (Tables 1 and 2).

Hence only under the preceding conditions can the $\mathrm{Ni}(\mathrm{OH})_{2}$ be described as a homogeneous thickness layer whose composition in terms of the $\mathrm{H}_{2} \mathrm{O}: \mathrm{NiO}$ molar ratio changes in the direction perpendicular to the substrate. Then, provided that the size of nickel hydroxide particles is smaller than the wavelength of light used in the experiments and that $d$ is sufficiently small to neglect inhomogeneity effects, the refractive index of the composite $\mathrm{Ni}(\mathrm{OH})_{2}$ layer consisting of $\mathrm{Ni}(\mathrm{OH})_{2}$ and electrolyte domains can be approached through the Maxwell-Garnett expression [31]

$\frac{n_{\mathrm{e}}^{2}-n_{\mathrm{a}}^{2}}{n_{\mathrm{c}}^{2}+2 n_{\mathrm{a}}^{2}}=\frac{F\left(n_{\mathrm{f}}^{2}-n_{\mathrm{a}}^{2}\right)}{n_{\mathrm{f}}^{2}+n_{\mathrm{a}}^{2}}$

where $n_{\mathrm{a}}$ and $n_{\mathrm{f}}$ are the refractive indices of the electrolyte and $\mathrm{Ni}(\mathrm{OH})_{2}$ respectively and $n_{\mathrm{e}}=n_{\mathrm{e}}-\mathrm{i} k_{\mathrm{e}}$ is the effective refractive index of the composite layer, which contains a volume fraction $F$ of $\mathrm{Ni}(\mathrm{OH})_{2}$, probably as $\alpha-\mathrm{Ni}(\mathrm{OH})_{2}$, for the initially precipitated layer. The dependences of the imaginary and real parts of $n_{\mathrm{e}}$ on $F$ are shown in Figs. 7(a) and 7(b) for $0 \leq k \leq 0.3$ and $1.35 \leq n \leq 1.39$. These plots show a linear dependence of $n$ on $F$ and can be rather satisfactorily compared with those exhibited in Fig. 6, considering that $Q_{\mathrm{c}}$ is directly proportional to $F$.

\section{The influence of ORCs}

Let us attempt to interpret the ellipsometric changes occurring during the application of ORCs to the nickel hydroxide electrode.

The faradaic yields of processes occurring during the ORCs should depend on the degree of coupling between the electrical perturbation and the rate of the proper electrochemical reactions. The extent of this coupling should also be extremely dependent upon the current distribution at the working electrode. It is known that the current distribution at disk electrodes in the ellipsometric cell design is far from ideal. Consequently, for each ORC a different radial distribution of the oxidized and reduced forms of $\mathrm{Ni}(\mathrm{OH})_{2}$ would be obtained. Therefore after a sufficiently prolonged number of ORCs a stationary situation should be attained. However, the fact is that under ORC conditions the $\mathrm{Ni}(\mathrm{OH})_{2}$ layer can be considered as a mixture of Nickel(II) hydroxide, nickel(III) hydroxide and electrolyte $-\mathrm{H}_{2} \mathrm{O}$ domains, so that another inhomogeneity effect in the direction parallel to the electrode is then added.

For the composite nickel hydroxide layer involving domains of active and inactive matcrial, an increase in $N$ would also tend to increase the volume fraction of the nickel hydroxide, i.e. the specific gravity of the nickel hydroxide layer, so that $d$ remains unchanged. 


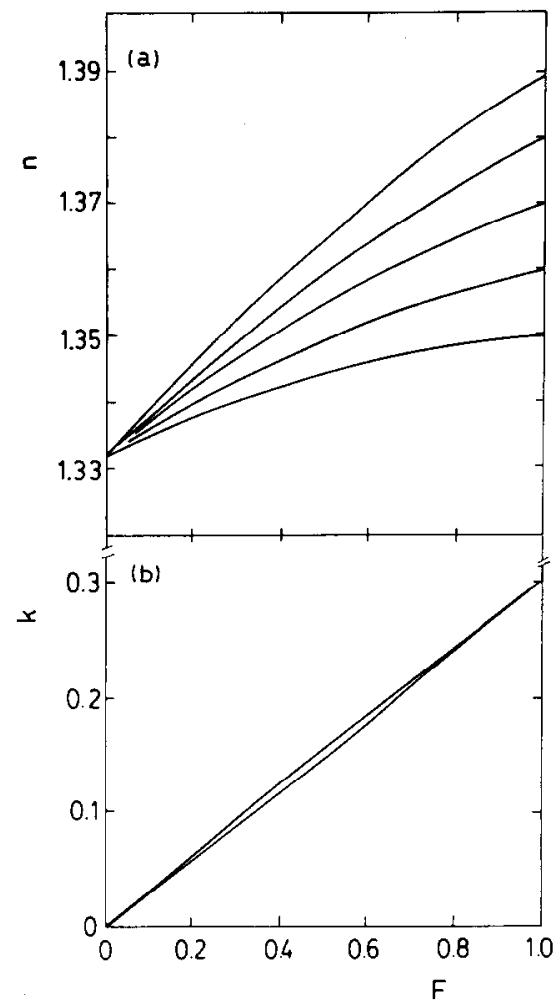

Fig. 7. Dependence of $n_{\mathrm{e}}$ and $k_{\mathrm{e}}$ on $F$, the volume fraction of $\mathrm{Ni}(\mathrm{OH})_{2}$, according to eqn. (1).

The change in the relative amounts of active material during the ORCs is confirmed by the small decrease in the voltammetric charge (anodic and cathodic) during the ORCs. Under these conditions, from the values of $\Delta$ and $\Psi$ one can tentatively deduce the changes in $n$ and $d$ occurring during the ORCs including long-range term treatments. The progressive processes occurring at the interface during the ORCs can be put forward as follows:

$\mathrm{Pt} / \mathrm{Ni}(\mathrm{OH})_{2}(x), \mathrm{H}_{2} \mathrm{O}(y), \mathrm{OH}^{-}(z)$

(1st OC) $\downarrow$

$\mathrm{Pt} / \mathrm{Ni}(\mathrm{OH})_{2}(x-p), \mathrm{NiOOH}(p), \mathrm{H}_{2} \mathrm{O}(y+p), \mathrm{OH}^{-}(z-p)$

(1st RC) $\downarrow \quad(p<x)$

$\mathrm{Pt} / \mathrm{Ni}(\mathrm{OH})_{2}\left(x-p+p^{\prime}\right), \mathrm{NiOOH}\left(p-p^{\prime}\right), \mathrm{H}_{2} \mathrm{O}\left(y+p-p^{\prime}\right), \mathrm{OH}^{-}\left(z-p+p^{\prime}\right)$ 
(2nd OC) $\downarrow \quad\left(p^{\prime}<p\right)$

$\mathrm{Pt} / \mathrm{Ni}(\mathrm{OH})_{2}\left(x-p+p^{\prime}-p^{\prime \prime}\right), \mathrm{NiOOH}\left(p-p^{\prime}+p^{\prime \prime}\right), \mathrm{H}_{2} \mathrm{O}\left(y+p-p^{\prime}+p^{\prime \prime}\right)$,

$$
\mathrm{OH}^{-}\left(z-p+p^{\prime}-p^{\prime \prime}\right)
$$

$$
\downarrow\left(p^{\prime \prime}<p^{\prime}<p\right)
$$

so that $\Sigma(-1)^{n+1} p_{n} \Rightarrow x$ on increasing the number of ORCs, which corresponds to a limiting situation involving total conversion of the active material. In practice this situation can also be achieved through a prolonged potential holding at $0.83 \mathrm{~V}$.

Hence along the ORCs the relative extension of the oxidized and reduced forms of the $\mathrm{Ni}(\mathrm{OH})_{2}$ changes, and this can explain the time effect of the reflectivity and ellipsometric parameters which are observed by holding the potential in the range where either the oxidized or reduced forms of the nickel hydroxide layers are supposedly stable species (Figs. 3 and 4). These changes are reflected principally through the values of $k_{\mathrm{O}}$ and $k_{\mathrm{R}}$, though the former changes less remarkably than the latter.

\section{The $\mathrm{Ni}(\mathrm{OH})_{2}$ electrode reaction pathway}

The entire electrochemical reaction can be described by the complex pathway reported in the literature involving $\alpha$ - and $\beta-\mathrm{Ni}(\mathrm{OH})_{2}, \beta$ - and $\alpha-\mathrm{NiOOH}$ and other intermediate species $[13,14]$. The reaction proceeds through a mechanism where the electrochemical reactions are coupled to chemical reactions. In addition, the electrochemical reactions produce a local change in $\mathrm{pH}$ at the reaction layer, i.e. the $\mathrm{pH}$ decreases during the anodic process and increases during the cathodic process $[13,14]$. This means that in addition to the above-mentioned processes the possible formation of soluble $\mathrm{Ni}^{2+}$ at the surface during the anodic reaction and $\mathrm{NiO}_{2}^{-}$during the cathodic reaction should not be discarded. Nevertheless, if soluble species are really formed, one can also expect that precipitation of $\mathrm{Ni}(\mathrm{OH})_{2}$ will take place somewhere in a region adjacent to the interface. In this case the distribution of active material on the electrode surface should change as cycling progresses and the nickel hydroxide layer thickness should become dependent on the electrode shape. Then reconstruction of the non-uniformly distributed $\mathrm{Ni}(\mathrm{OH})_{2}$ layer on the platinum substrate should occur.

The present results suggest that the nickel hydroxide reaction pathway (2a)-(2d) is applicable to the domains of oxidized and reduced forms of the $\mathrm{Ni}(\mathrm{OH})_{2}$ layer provided that the corresponding reaction starts at the border of domains and extends inwards as has been proposed for thick $\mathrm{Ni}(\mathrm{OH})_{2}$ electrodes used in alkaline batteries [32].

Obviously, in the time range of the ORCs used at present it is likely that the aging effect plays a minor role as compared to changes in the relative extension of the reduced and oxidized $\mathrm{Ni}(\mathrm{OH})_{2}$ domains. Accordingly, the value of $d$ derived 
from ellipsometry cannot be compared directly with the average value of $d$ resulting from voltammetry. Moreover, the contribution of the local precipitation of $\mathrm{Ni}(\mathrm{OH})_{2}$ should increase in those regions where the current density becomes greater. In the present cell design these regions are located at the border of the platinum disc substrate $[33,34]$. This is what should be expected for a local decrease in the water content of the nickel hydroxide layer. Therefore all these facts together, with the possible formation of traces of $\mathrm{O}_{2}$ at $0.8 \mathrm{~V}$, can explain why the $Q_{\mathrm{a}} / Q_{\mathrm{c}}$ ratio in these experiments turned out to be slightly greater than unity.

\section{ACKNOWLEDGMENT}

A grant for scientific research from the Consejo Nacional de Investigaciones Científicas y Técnicas de Argentina is acknowledged.

\section{REFERENCES}

1 Yu.N. Chernykh and A.A. Yakovleva, Elektrokhimiya, 7 (1971) 530.

2 M.A. Hopper and J.L. Ord, J. Electrochem. Soc., 120 (1973) 183.

3 J.L. Ord, J.C. Clayton and D.J. De Smet, J. Electrochem. Soc., 124 (1977) 1714.

4 W. Visscher and E. Barendrecht, J. Electroanal. Chem., 154 (1983) 69.

5 W. Paik and Z. Szklarska-Smialowska, Surf. Sci., 96 (1980) 401.

6 C.A. Melendres, W. Paden, B. Tani and W. Walczak, J. Electrochem. Soc., 134 (1987) 762.

7 J. McBreen, W.E. O'Grady, K.I. Pandya, R.W. Hoffman and D.E. Sayers, Langmuir, 3 (1987) 428.

8 N. Hara and K. Sugimoto, J. Jpn. Inst. Met., 47 (1983) 31.

9 F. Hahn, B. Beden, M.J. Croissant and C. Lamy, Electrochim. Acta, 31 (1986) 355.

10 C. Zhenga and S.M. Park, in E. McCafferty and R.J. Brodd (Eds.), Surfaces, Inhibition and Passivation, Electrochemical Society, Pennington, NJ, 1986, 267.

11 H. Bode, K. Dehmelt and J. Witte, Electrochim. Acta, 11 (1966) 1079.

12 J.L. Ord, Surf. Sci., 56 (1976) 413.

13 R.S. Schrebler Guzmán, J.R. Vilche and A.J. Arvia, J. Electrochem. Soc., 125 (1978) 1578.

14 R.S. Schrebler Guzmán, J.R. Vilche and A.J. Arvia, J. Appl. Electrochem., 9 (1979) 183.

15 C.A. Melendres and S. Xu, J. Electrochem. Soc., 131 (1984) 2239.

16 P.L. Loyselle, P.J. Karjala and B.C. Cornilso, in J.R. Selman and H.C. Marn (Eds.), Electrochemical and Thermal Modeling of Battery, Fuel Cell, and Photoenergy Conversion Systems, Electrochemical Society, Pennington, NJ, 1986, pp. 114-121.

17 W. Visscher and E. Barendrecht, Surf. Sci., 135 (1983) 436.

18 W. Visscher, J. Phys. (Paris), 44 (1983) 213.

19 A.A. Wronkowska, A. Wronkowski and J. Pakulska, Acta Univ. Wratislawiensis, 937 (1986) 145.

20 A.M. Ivanov, L.A. Sal'nikov, L.P. Timofeeva and L.O. Favovskaya, Elektrokhimiya, 21 (1985) 1287.

21 P. Oliva, J. Leonardi, J.F. Laurent, C. Delmas, J.J. Braconnier, M. Fligartz, F. Fievet and A. de Guibert, J. Power Sources, 8 (1982) 229.

22 M.E. Folquer, J.R. Vilche and A.J. Arvia, J. Electrochem. Soc., 127 (1980) 263.

23 B.D. Cahan and C.-T. Chen, J. Electrochem. Soc., 129 (1982) 922.

24 C.P. De Pauli, M.C. Giordano and J.O. Zerbino, Electrochim. Acta, 28 (1983) 1781.

25 R.H. Muller and C.G. Smith, Surf. Sci., 96 (1980) 375.

26 R.H. Muller, Adv. Electrochem. Electrochem. Eng., 9 (1973) 212.

27 S. Gottesfeld and S. Srinivasan, Report NTIS/5285, 1975, Department of Applied Science, Brookhaven; available from US Department of Commerce, Port Royal Road, Springfield, VA 22161, USA. 
28 C. Barbero, J. Zerbino, L. Sereno and D. Posadas, Electrochim. Acta, 32 (1987) 693.

29 W.J. Plieth, J. Zerbino, C. Lahnann and G. Kossmehl, J. Electroanal. Chem., 274 (1989) 213.

30 A.G. Walton, The Formation and Properties of Precipitates, Wiley, New York, 1967.

31 D.E. Aspness, in E.D. Palik (Ed.), Handbook of Optical Constants of Solids, Scientific Press, New York, 1985, p. 104.

32 J. Newman, J. Electrochem. Soc., 113 (1966) 501; 113 (1966) 1235.

33 P.C. Milner and U.B. Thomas, Adv. Electrochem. Electrochem. Eng., 5 (1966) 1.

34 J. Newman, J. Electrochem. Soc., 113 (1966) 501, 1235. 